\title{
In the search of novel urine biomarkers for the early diagnosis of prostate cancer. Intracellular or secreted proteins as the target group? Where and how to search for possible biomarkers useful in the everyday clinical practice
}

\author{
Amalia Katafigioti ${ }^{1}$, Ioannis Katafigiotis ${ }^{1}$, Stavros Sfoungaristos ${ }^{2}$, Christos Alamanis ${ }^{1}$, \\ Konstantinos Stravodimos ${ }^{1}$, Ioannis Anastasiou ${ }^{1}$, Eleni Roumelioti ${ }^{1}$, Mordechai Duvdevani ${ }^{2}$, \\ Constantinos Constantinides ${ }^{1}$ \\ 1 1st University Urology Clinic, Laiko Hospital, Athens, Greece; \\ ${ }^{2}$ Hebrew Hadassah University Medical Center, Jerusalem, Israel.
}

\begin{abstract}
Summary Objective: To search which category of proteins can be detected in urine in order to examine subsequently its ability to improve our accuracy for the diagnosis of Prostate Cancer (PCa) as biomarkers in clinical useful fluids like urine and serum.

Material and method(s): Urine samples of 127 patients were obtained after a vigorous transrectal prostatic massage to both lobes. The patients were considered to have a high risk for PCa according to their PSA (> $4 \mathrm{ng} / \mathrm{ml})$, their digital rectal examination (DRE) (positive for suspicious prostatic lesions) or to their abnormal PSA kinetics (PSA velocity (PSAV >0.75 ng/mL). All patients subsequently were subjected to an extended 10-core per prostatic lobe TRUS-b (total 20 prostatic samples). The proteins that were chosen to be detected in the urine samples with Western-blot, as possible biomarkers, were Glutathione peroxidase 3 precursor (GPX3), Cofilin-1 (CFL1), Heat shock protein-90ß (HSP 90ß), Zinc alpha 2-glycoprotein (ZAG) and secreted protein acidic and rich in cysteine (SPARC). These proteins have been detected previously in the prostatic tissue by proteomics proving their discriminative ability between patients with prostate cancer and benign prostatic hyperplasia.

Result(s): From the five proteins, only the secreted Zinc alpha 2-glycoprotein was detected in urine showing a promising ability in the improvement of our diagnostic accuracy for the early diagnosis of prostate cancer.

Conclusions: From various categories of proteins that have already been detected in the tissue of prostate by proteomics, only secreted protein Zinc alpha 2-glycoprotein showed a clear signal in the urine, proving its discriminative potential for the early diagnosis of PCa.
\end{abstract}

KEY WORDS: Prostate cancer; Biomarker; Urine;

Zinc alpha 2-glycoprotein.

Submitted 14 February 2016; Accepted 8 May 2016

\section{INTRODUCTION}

Prostate cancer ( $\mathrm{PCa}$ ) constitutes the most common cancer and the second cause of cancer specific death in men (1). The widespread use of Prostate Specific Antigen (PSA) test has revolutionized PCa diagnosis. In fact the rise of PCa incidence over the last 20 years has been attributed also to the PSA (2). Nevertheless, PSA is a test specific for the prostate but not specific for cancer and it can be elevated due to benign prostatic hyperplasia (BPH) and prostatitis. While the conventional PSA threshold of $4 \mathrm{ng} / \mathrm{ml}$ has been used in the previous years as a recommendation for transrectal ultrasound guided biopsy (TRUS-b), today PSA is considered a continuous parameter with higher levels of the test rising the likelihood of PCa (3). PCa can be present despite low PSA values and even aggressive PCa with Gleason score $>7$ can be diagnosed with low serum PSA values, precluding the definition of an optimal PSA threshold for the early diagnosis of PSA and constituting the urgent need of more specific biomarkers for PCa $(3,4)$.

In our study we tried to examine prospectively, various proteins in the urine of patients with suspect of $\mathrm{PCa}$ according to their PSA values or their digital rectum examination (DRE), who subsequently were subjected to TRUS-b. Five proteins were meticulously chosen. Four were previously detected by the use of proteomics in the tissue of patients with (BPH) and $\mathrm{PCa}$ helping to differentiate these two diseases, while the fifth was chosen due to its proven utility as a secreted protein in bladder cancer $(5,6)$. At the same time we classified the proteins in two major categories intracellular and secreted. Our goal was to see which category of proteins can be detected in urine in order to examine subsequently its ability to help us improve our diagnostic accuracy for the PCa as biomarker in clinical useful fluids like urine and serum.

\section{Materials AND MEthodS}

Urine samples of 127 patients were obtained after a vigorous transrectal prostatic massage to both lobes and they were immediately stored to $-80^{\circ} \mathrm{C}$. The patients were considered to have high risk for PCa according to their PSA (> $4 \mathrm{ng} / \mathrm{ml}$ ), their digital rectal examination (DRE) (positive for suspicious prostatic lesions) or to their abnormal PSA kinetics (PSA velocity (PSAV > 0.75

No conflict of interest declared. 
$\mathrm{ng} / \mathrm{mL}$ ). All patients subsequently were subjected to an extended 10-core per prostatic lobe TRUS-b (total 20 prostatic samples). The specimen was analyzed in a blinded fashion by an experienced uropathologist (K.P.) and the results of the histology were collected. Exclusion criteria were patients with known PCa, PSA > $25 \mathrm{ng} / \mathrm{ml}$, patients taking finasteride or dutasteride, patients who had been previously subjected to a TRUS-b or to an operation for BPH and patients with rectal extirpation. Patients with PSA > $25 \mathrm{ng} / \mathrm{ml}$ were excluded due to the fact that as PSA rises, the probability of PCa also increases and the goal was to examine specific the patients that could cause diagnostic dilemma to the urologist and how urine biomarkers could help to the differential diagnosis and no these that Pca diagnosis was higher based to the PSA. Nevertheless PSA > $25 \mathrm{ng} / \mathrm{ml}$ was a random choice based on the higher probability of PCa. The study was approved by the ethical committee of the Athens University Medical School and LAIKO Hospital and all the patients signed a written consent after a detailed information.

\section{Urine samples-proteins-Western blot}

The proteins that was chosen to be detected in the urine samples as possible biomarkers were Glutathione peroxidase 3 precursor (GPx3), Cofilin-1 (CFL1), Heat shock protein-90 $\beta$ (HSP 90ß), Zinc alpha 2-glycoprotein (ZAG) and secreted protein acidic and rich in cysteine (SPARC). GPx3, CFL1, HSP 90 $\beta$, ZAG, were chosen based on their performance in the tissue with the use of quantitative proteomics analysis in a previous study of ours, where all these four proteins showed different levels between BPH tissue (obtained from suprapubic prostatectomy or transurethral prostatectomy) and PCa tissue (obtained from radical retropubic prostatectomy) 5 (Table 1). Specifically, GPx3 was up-regulated $(2.19 \pm 0.57$ fold change) in PCa compared to BPH tissue, CFLl was also up-regulated (3.29 \pm 1.20 fold change) in PCa compared to BPH tissue, HSP $90 \beta$ was also up-regulated ( $3.2 \pm 0.61$ fold change) in PCa compared to BPH tissue, while ZAG was down-regulated $(0.43 \pm 0.13$ fold change $)$ in $\mathrm{PCa}$ compared to BPH5 (Table 1). The fifth protein SPARC was detected from another study of our team, where this protein was found to be differentially expressed at statistically significant levels in the secretome of a cell line model for aggressive bladder cancer, and due its performance and its secreted nature was also chosen in order to examine its possible utility in $\mathrm{PCa}$ (6) (Table 1).

\section{Sample preparation}

Urine samples were thawed on ice. Trichloroacetic acid (TCA) with the carrier sodium lauroyl sarcosinate (NLS) precipitation was conducted as followed: $0.1 \%$ NLS $7.5 \%$ TCA was added to every sample. Samples were vortexed and incubated at $-20^{\circ} \mathrm{C}$ o/n. Samples were thawed and centrifuged at $10.000 \mathrm{~g}$ for $10 \mathrm{~min}$ at $4^{\circ} \mathrm{C}$. Protein pellet was washed with ice cold Tetrahydrofuran (THF) and centrifuged at $10.000 \mathrm{~g}$ for $10 \mathrm{~min}$ at $4^{\circ} \mathrm{C}$. Washing step was repeated one more time. Pellet was resuspended in lysis buffer (7M Urea, 2M Thiourea, 4\% CHAPS, 1\% DTE, $2 \%$ IPG). Bath sonication was performed for $30 \mathrm{~min}$ and finally samples were centrifuged at $10.000 \mathrm{~g}$ for $10 \mathrm{~min}$ RT; $3.6 \%$ protease inhibitors (Roche) were added to the supernatant and stored at $-20^{\circ} \mathrm{C}$ until used.

\section{Western blot analysis}

Total protein $(20 \mu \mathrm{g})$ of urine samples were separated by $10 \%$ SDS-PAGE under reducing conditions and electroblotted to Hybond-ECL nitrocellulose membrane (Amersham Biosciences). After blocking with 5\% non-fat dried milk in TBST (20 mM Tris/pH 7.6, $137 \mathrm{mM} \mathrm{NaCl}$, $0.1 \%$ Tween 20 ) for $2 \mathrm{~h}$ at room temperature, membranes were washed with TBST and incubated overnight at $4{ }^{\circ} \mathrm{C}$ with the primary antibodies, as applicable: mouse antihuman SPARC (Santa Cruz; dilution 1:500), mouse antihuman ZAG (Santa Cruz; dilution 1:1000), mouse antihuman cofilin (Santa Cruz; dilution 1:2000), mouse antihuman GPx-3 (Santa Cruz; dilution 1:1000), goat antihuman HSP90b (Santa Cruz; dilution 1:3000). Membranes were then washed with TBST and incubated with antimouse or antigoat HRP-conjugated secondary antibody (Santa Cruz; dilution 1:10 000) for $2 \mathrm{~h}$ at room temperature. A final wash with TBST was made and target protein was detected by Enhanced Chemiluminescence (Perkin-Elmer LAS, Inc.) detection system. Films were scanned and images were analyzed using Quantity One software (Bio Rad).

\section{RESULTS}

Sample baseline characteristics are presented in Table 2.

Table 1.

Proteins of the study.

\begin{tabular}{|c|c|c|c|c|}
\hline Proteins & Nature & $\begin{array}{l}\text { Performance in tissue between BPH } \\
\text { and PCa or other utility }\end{array}$ & Detection in urine & Explanation \\
\hline$\overline{\mathrm{GPX} 3}$ & Secreted & $\begin{array}{c}\text { Up-regulated } \\
(2.19 \pm 0.57 \text { fold change }) \text { in PCa }\end{array}$ & Detected in few samples & $\begin{array}{c}\text { Extensive unspecific binding } \\
\text { of the antibody }\end{array}$ \\
\hline$\overline{C F L 1}$ & Intracellular & $\begin{array}{c}\text { Up-regulated } \\
(3.29 \pm 1.20 \text { fold change }) \text { in PCa }\end{array}$ & $\begin{array}{l}\text { Not detected both in normal } \\
\text { and prostate cancer samples }\end{array}$ & Intracellular \\
\hline HSP 90ß & Intracellular & $\begin{array}{c}\text { Up-regulated } \\
(3.2 \pm 0.61 \text { fold change }) \text { in PCa }\end{array}$ & $\begin{array}{l}\text { Not detected both in normal } \\
\text { and prostate cancer samples }\end{array}$ & Albumin masking effects \\
\hline SPARC & Secreted & $\begin{array}{l}\text { Expressed at statistically significant } \\
\text { levels in aggressive bladder cancer }\end{array}$ & $\begin{array}{l}\text { Not detected both in normal } \\
\text { and prostate cancer samples }\end{array}$ & Intracellular \\
\hline$\overline{Z A G}$ & Secreted & $\begin{array}{c}\text { Down-regulated } \\
(0.43 \pm 0.13 \text { fold change }) \text { in } \mathrm{PCa}\end{array}$ & $\begin{array}{l}\text { Significant increase in patients } \\
\text { with positive histology for PCa }\end{array}$ & Secreted \\
\hline
\end{tabular}


Table 2.

Demographics and clinical characteristics.

\begin{tabular}{|lc|}
\hline & N (\%) \\
\hline Age (years), mean (SD) & $65.7(8.7)$ \\
\hline BMI (kg/m²), mean (SD) & $27.5(3.5)$ \\
\hline Smoking & $44(34.6)$ \\
No & $48(37.8)$ \\
Ex-smoker & $35(27.6)$ \\
Yes & \\
\hline Family history of cancer & $60(47.2)$ \\
No & $67(52.8)$ \\
Yes & \\
\hline Family history of prostate cancer & $102(80.3)$ \\
No & $25(19.7)$ \\
Yes & $9.1(5.3)$ \\
\hline PSA (ng/mL), mean (SD) & $6(4.7)$ \\
\hline PSA (ng/mL) & $89(70.1)$ \\
< 4 & $32(25.2)$ \\
4-10 & $68(54.0)$ \\
$>10$ & $59(46.0)$ \\
\hline DRE & \\
Negative & $56(44.1)$ \\
Positive & $29(22.8)$ \\
\hline Histology & $42(33.1)$ \\
No PCa & 45 \\
High grade PIN & \\
PCa & \\
Prostate volume (ml) & \\
\hline BMI, body mass index; High grade PIN, prostatic intraepithelial neoplasia. \\
\hline
\end{tabular}

Figure 1.

Western blot analysis of Glutathione peroxidase 3 precursor (GPx3).

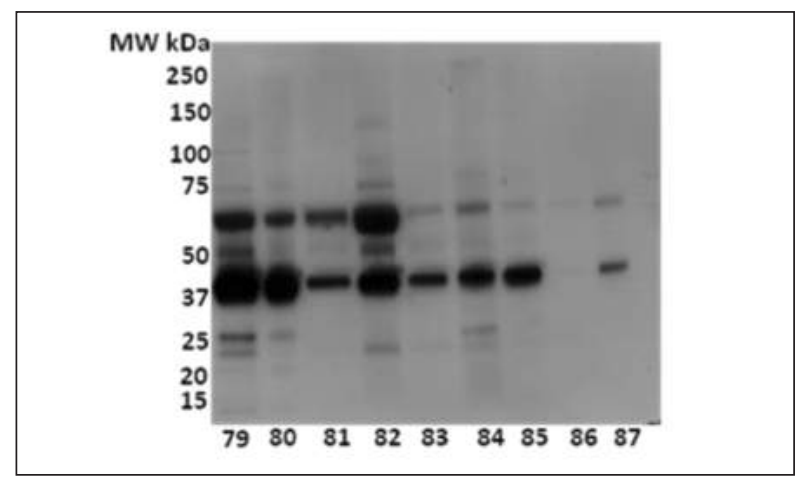

GPx-3

A representative image of western blot analysis of urine samples with Anti-GPx-3 (MW: $23 \mathrm{kDa}$ ) is depicted in Figure 1. Glutathione peroxidase 3 is a secreted protein that protects cells and enzymes from oxidative damage, by catalyzing the reduction of hydrogen peroxide, lipid peroxides and organic hydroperoxide, by glutathione (7). This protein has been previously found to be up-regulated (2.19 \pm 0.57 fold change) in PCa compared to $\mathrm{BPH}$ tissue specimens by a quantitative proteomics analysis (5) (Table 1). GPx-3 was detected in a few samples $(79,80,84)$. This was mainly attributed due to the extensive unspecific binding of the antibody as shown in Figure 1. Many optimization protocols were applied to reduce the effect of unspecific binding (lower amount of starting material loaded on the gel, different antibody
Figure 2.

Western blot analysis of Cofilin-1 (CFL1),

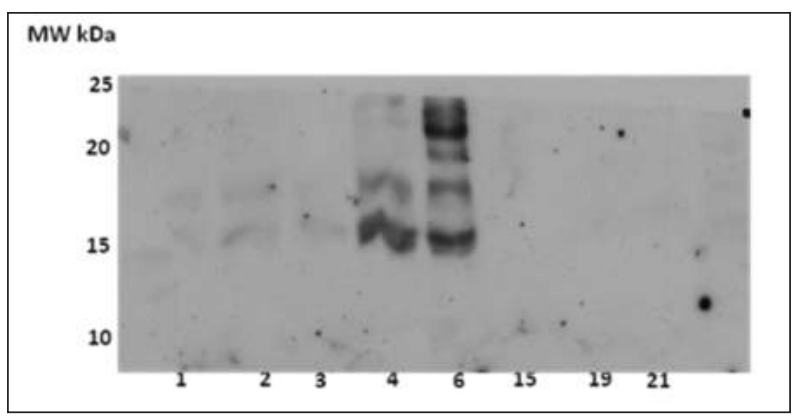

dilutions and incubation times, different blocking times, different enhanced chemiluminescence detection systems, different film exposure times) without any improvement on the results obtained.

\section{Cofilin-1}

Representative image of western blot analysis of urine samples with Anti-Cofilin 1 (MW: 19-21 kDa) is depicted in Figure 2. Cofilin-1 is an intracellular protein that regulates actin cytoskeleton dynamics. It plays a role in the regulation of cell morphology and cytoskeletal organization (8). It has been also found to be up-regulated $(3.29 \pm 1.20$ fold change $)$ in PCa compared to BPH tissue specimens by a quantitative proteomics analysis (5) (Table 1.). However, cofilin-1 was not detected in both normal $(1,2,3,4)$ and PCa $(6,15,19,21)$ urine samples as shown in Figure 2. An explanation for this could be the fact that cofilin-1 is an intracellular protein which reduces the chances to be detected in biological fluids such as urine.

\section{SPARC}

Western blot analysis of Anti-SPARC (MW: $43 \mathrm{kDa}$ ) in urine samples is depicted in Figure 3. SPARC is a secreted protein that appears to regulate cell growth through interactions with the extracellular matrix and cytokines (6). It binds calcium and copper, several types of collagen, albumin, thrombospondin, PDGF and cell membranes (6).

\section{Figure 3.}

Western blot analysis of secreted protein acidic and rich in cysteine (SPARC).

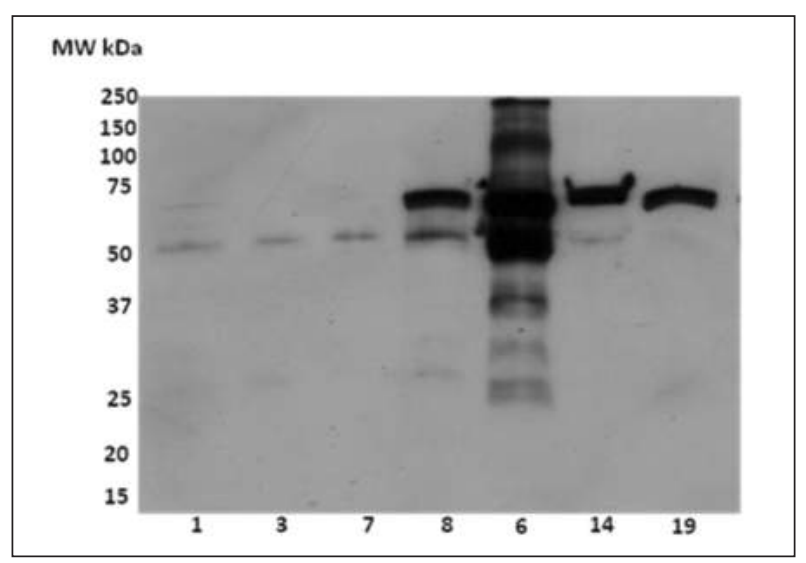


This protein was found to be differentially expressed at statistically significant levels in the secretome of a cell line model for aggressive bladder cancer (6). SPARC could not be detected in both normal $(1,3,7,8)$ and $\mathrm{PCa}(6,14,19)$ urine samples as shown in Figure 3. In most cases a band of 60-70 kDa was detected corresponding to the MW of albumin. SPARC binds to albumin which is present in urine samples making SPARC detection quite difficult due to albumin masking effects.

\section{HSP 90 $\beta$}

Western blot analysis of Anti-HSP 90 (MW: $90 \mathrm{kDa}$ ) in urine samples is depicted in Figure 4. HSP $90 \beta$ is an intracellular protein that acts as a molecular chaperone promoting the maturation, structural maintenance and proper regulation of specific target proteins involved in many functions such as: cell cycle control and signal transduction (9). This protein has been found to be up-regulated (3.2 \pm 0.61 fold change) in PCa compared to BPH tissue specimens by quantitative proteomics analysis (5). HSP $90 \beta$ was not detected in urine samples mainly because of its intracellular location which does not allow for its detection in body fluids such as urine (Figure 4).

\section{Figure 4.}

Western blot analysis of Heat shock protein-90ß (HSP 90ß).

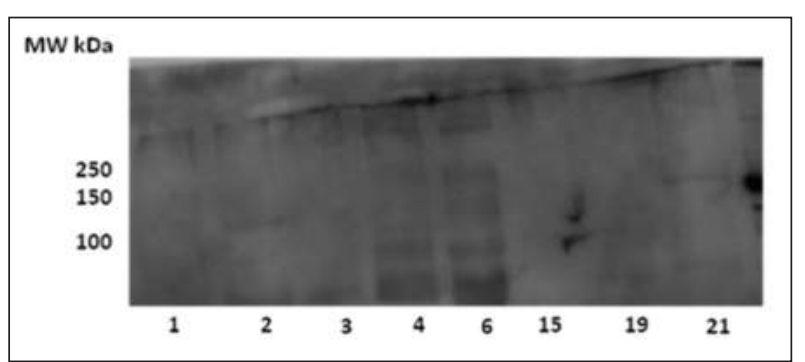

\section{Statistical analysis (Table 2 and 3)}

Continuous variables are presented as mean and standard deviation or median and interquartile range (IQR) while qualitative variables are presented as absolute and relative frequencies. The Kruskal-Wallis test was used for the com- parison of the five proteins between different patient groups. All P values reported are two-tailed. Statistical signifi cance was set at 0.05 and analyses were conducted using STATA statistical software (version 9.0).

\section{ZAG}

Western blot analysis of urine samples with Anti-ZAG (MW: $47 \mathrm{kDa}$ ) is depicted in Figure 5. ZAG is a secreted protein which stimulates lipolysis in adipocytes and is responsible for the reduction of fat which is associated with some advanced cancers $(10,11)$. ZAG was found to be down-regulated $(0.43 \pm 0.13$ fold change $)$ in $\mathrm{PCa}$ compared to BPH tissue specimens by quantitative proteomics analysis (5). Contrary to the downregulation of ZAG in tissues, ZAG in urine showed a significant increase in patients with positive histology for PCa. ZAG levels were significantly increased as PSA was increased $(\mathrm{P}=0.005)$ and in the patients with positive histology for $\mathrm{PCa}(\mathrm{P}=0.004)$ (Table 3). ZAG due to its performance showing statistical significant differences between the urine of patients with BPH and PCa it was further analyzed and proved its utility at least in our preliminary results published by our group.

\section{Figure 5.}

Western blot analysis of Zinc alpha 2-glycoprotein (ZAG) $n$.

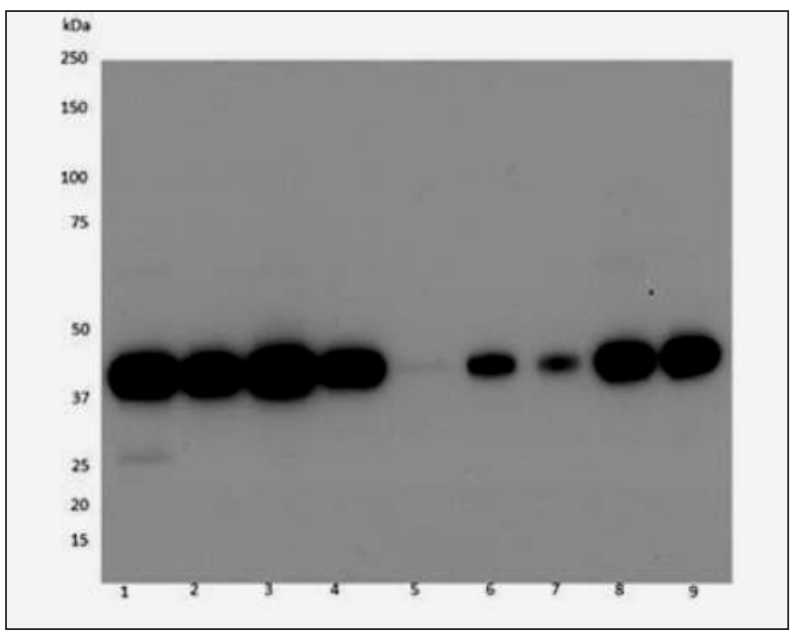

Table 3.

Kruskal - Wallis test - Association of five urine proteins with PSA levels, Gleason score and histology.

\begin{tabular}{|c|c|c|c|c|c|c|c|}
\hline & ZAG & & & GPx-3 & Cofilin-1 & SPARC & HSP $90 \beta$ \\
\hline & MEDIAN & IQR & $P$ & \multirow{13}{*}{$\begin{array}{l}\text { Protein that } \\
\text { detected only } \\
\text { in a few urine } \\
\text { samples }\end{array}$} & \multirow{13}{*}{$\begin{array}{l}\text { Not detected both } \\
\text { in normal } \\
\text { and Prostate } \\
\text { cancer samples }\end{array}$} & \multirow{13}{*}{$\begin{array}{l}\text { Not detected both } \\
\text { in normal } \\
\text { and Prostate } \\
\text { cancer samples }\end{array}$} & \multirow{13}{*}{$\begin{array}{l}\text { Not detected both } \\
\text { in normal } \\
\text { and Prostate } \\
\text { cancer samples }\end{array}$} \\
\hline$\overline{\text { PSA }}$ & & & & & & & \\
\hline $0-4$ & 0 & $0.0-0.1$ & 0.005 & & & & \\
\hline $4-10$ & 1.1 & $0.5-1.9$ & & & & & \\
\hline$>10$ & 1.4 & $0.8-2.9$ & & & & & \\
\hline \multicolumn{4}{|l|}{ Gleason score } & & & & \\
\hline $4-6$ & 1.2 & $1-2.9$ & 0.291 & & & & \\
\hline 7 & 1.4 & $1.3-2.8$ & & & & & \\
\hline $8-10$ & 1.9 & $1.5-3.2$ & & & & & \\
\hline \multicolumn{4}{|l|}{ Histology } & & & & \\
\hline Negative (BPH) & 1 & $0.3-1.8$ & 0.004 & & & & \\
\hline High grade PIN & 0.8 & $0.4-1.4$ & & & & & \\
\hline Adenocarcinoma & 1.4 & $1.2-3.0$ & & & & & \\
\hline
\end{tabular}




\section{Discussion}

The advent of proteomics made possible the identification of thousands of proteins among which, a large number of possible novel biomarkers especially for $\mathrm{PCa}$ $(5,12)$. PSA is the best example of a clinical useful biomarker and is still considered the best biomarker in our disposal for the early diagnosis of PCa. However, although it is organ specific, it is not disease specific and high levels of PSA $>4 \mathrm{ng} / \mathrm{ml}$ are not necessarily attributed to PCa, and at the same time PCa of high Gleason Score $>7$ can be diagnosed in low PSA levels $<4 \mathrm{ng} / \mathrm{ml}$, even lower than $<1 \mathrm{ng} / \mathrm{ml}$, while $75 \%$ of patients are submitted to high number of unnecessary TRUS-b due to their increased levels of PSA particularly those in the zone of $4-10 \mathrm{ng} / \mathrm{ml}(3,12,13)$. On the other hand the combination of the high diversity of the nature of $\mathrm{PCa}$, with the increase of the TRUS-b due to the use of PSA, has led to the "overdiagnosis" of PCa of low aggressiveness (Gleason score $</=6$ ) and subsequently to overtreatment with a serious operation like radical retropubic prostatectomy, for a disease that would possibly not affect their longevity and their quality of life (14). The confound results from the largest studies PCLO-ERSPC concerning PSA screening, and the inherent problems of PSA, resulted to the conclusion that the best use of PSA for PCa is that there is no cut-off point of PSA with sensitivity and specificity and PSA constitutes a continuous parameter, with higher levels indicating greater likelihood of $\mathrm{PCa}(11,15,16)$. As a result novel biomarkers are urgently needed in order to address the problems of PSA and taking into consideration that the long latency time of $\mathrm{PCa}$ and our ability to effectively manage at least the organ confined disease, $\mathrm{PCa}$ is the ideal candidate for a biomarker-based diagnosis and follow-up as PSA has already indeed proved. The problem is where and how to find new biomarkers and how to transit from the theory to the everyday clinical practice with a biomarker both sensitive and specific. Proteomics in tissue is perhaps the first step and our suggestion, since it can identify proteins which help differentiate PCa from other prostatic diseases $(5,12)$. We used the results of our previous work in order to examine the possible use of proteins that showed discriminative ability for $\mathrm{PCa}$ and after a thorough literature research we concluded to four proteins two intracellular (CLF1, HSP 90 $\beta$ ) and two secreted (GPx3, ZAG) that according to their biochemical effect could be analyzed in clinical useful fluids like urine. We also analyzed a fifth secreted protein (SPARC) that has been proved very useful in bladder cancer (6).

GPx3 is a secreted protein important for the protection of the cell from oxidative stress, which has been linked to cancer pathogenesis (7) and even though was found to be up-regulated $(2.19 \pm 0.57$ fold change $)$ in $\mathrm{PCa}$ compared to BPH tissue specimens (Table 1) (5), was detected in a few urine samples $(79,80,84)$, which was mainly attributed to the extensive unspecific binding of the antibody as shown in Figure 1 without the ability to overcome this problem. We then chose and analyzed CLFl both because is an intracellular protein regulating cell morphology and cytoskeletal organization, which theoretically is disrupted in cancerous procession (8) and because it has been found to be up-regulated (3.29 \pm 1.20 fold change) in PCa compared to BPH tissue specimens (table 1) (5), but was not detected in both normal $(1,2,3,4)$ and $\mathrm{PCa}(6,15,19,21)$ urine samples as shown in Figure 2, which could be explained by its intracellular nature,

HSP $90 \beta$ also an intracellular protein which is important for the structural maintenance and the signal transduction of the cell, mechanisms which are disorganized in the cancerous procession (9), was found to be up-regulated (3.2 \pm 0.61 fold change) in PCa compared to BPH tissue specimens (5), but again was not detected in urine samples (Figure 4), that could also be explained by its intracellular location. SPARC is a secreted protein responsible for the cell growth interacting with extracellular matrix found to be connected with the aggressiveness of bladder cancer (6). We chose to analyze SPARC for PCa in urine due to its clear effect in our previous study6, but again this protein could not be detected in both normal $(1,3,7,8)$ and PCa $(6,14,19)$ urine samples as shown in Figure 3, due to the masking effects of albumin from the binding with SPARC. The last protein was ZAG a secreted protein which stimulates lipolysis in adipocytes, leading to the development of cachexia and advanced cancer stages $(10,11)$ which was found to be down-regulated $(0.43 \pm 0.13$ fold change) in PCa compared to BPH tissue specimens (5). ZAG in urine showed a very clear signal (Figure 5) with significant increase in patients with positive histology for PCall and its further utility as a possible novel urine biomarker has already been examined from our team (11) (Table 3). ZAG levels were significantly increased as PSA was increased (P $=0.005)$ and in the patients with positive histology for PCa $(\mathrm{P}=0.004)$ (Table 3$)$.

It is clear that proteomics help us both to detect the proteome of a tissue and to quantify the differences between normal and pathogenic cells $(5,12)$. But tissue is not a clinical useful material for the everyday clinical practice due to the need of invasive methods for the specimen and of course due to the fact that tissue sampling means a final pathologist histology diagnosis based on the cell regardless of a biomarker (12). Urine is perhaps the easiest to obtain biological fluid without causing any distress to the patient and already a large number of different markers in the literature have been detected as possible biomarkers for $\mathrm{PCa}$ such as sarcosine, annexin A3, TMPRSS2:ERG fusion gene and PCA3, with the latter being already an established urine biomarker incorporated to official guidelines $(11,17)$. On the other hand urine is a difficult biological fluid to analyze because of its complex nature with abundant compounds interfering with the electrophoretic migration of other proteins constituting the detection of biomarkers in some cases very difficult (18). Nevertheless from the four proteins we chose to detect in urine based on their previous proteomic performance in tissue (GPx-3, CLF1, HSP 90 $\beta$, ZAG) and the fifth protein that was chosen according to its utility in bladder cancer (SPARC) only ZAG, a secreted protein, showed not only a clear signal (Figure 5) but the ability to help in the discrimination of PCa (11). It seems that perhaps secreted proteins like ZAG and of course PSA may be easier to detect and analyze in urine. 
The detection of a protein in tissue, even the ones that have statistical significant different levels between PCa and BPH, doesn't mean that this protein will be automatically detected in a clinical useful fluid like urine. The combination of a protein with discriminative levels in tissue, with pathophysiology route allowing its presence in urine in different levels between normal and cancerous samples and of course a biochemistry compatible with our detection abilities is needed in order to find and establish a clinical useful biomarker in urine.

\section{Conclusions}

Proteomics in tissue of known histology may be the first step to spot new possible biomarkers. The goal is to detect these proteins to clinical useful fluids like urine and serum for the early diagnosis of $\mathrm{PCa}$. A protein that has proved already its efficacy in tissue doesn't mean automatically that it would be also useful in urine and serum.

Various factors like the pathophysiology of the proteins and our methodology may contribute to the inability of the detection of a protein to urine. In our case form the five proteins GPx3, CFL1, HSP 90 $\beta$, ZAG and SPARC, only a secreted protein ZAG has been detected and proved its efficacy both in tissue and in urine.

\section{RefEREnCES}

1. Siegel R, Naishadham D, Jemal A. Cancer statistics, 2012. CA Cancer J Clin. 2012; 62:10-29.

2. Fitzpatrick JM, Schulman C, Zlotta AR, Schröder FH. Prostate cancer: a serious disease suitable for prevention. BJU Int. 2009; 103:864-70.

3. Tosoian J, Loeb S. PSA and beyond: the past, present, and future of investigative biomarkers for prostate cancer. Scientific World Journal. 2010; 10:1919-31.

4. Thompson IM, Pauler DK, Goodman PJ, et al. Prevalence of prostate cancer among men with a prostate-specific antigen level < or $=4.0 \mathrm{ng}$ per milliliter. N Engl J Med. 2004; 350:2239-46.

5. Garbis SD, Roumeliotis T, et al. Search for potential markers for prostate cancer diagnosis, prognosis and treatment in clinical tissue specimens using amine specific isobaric tagging (iTRAQ) with twodimensional liquid chromatography and tandem mass spectrometry. J Proteome Res. 2008; 7:3146-58.

6. Makridakis M, Roubelakis MG, Bitsika V, et al. Analysis of secreted proteins for the study of bladder cancer cell aggressiveness. J Proteome Res. 2010; 9:3243-59.

7. El Haddad M, Jean E, Turki A, et al. Glutathione peroxidase 3, a new retinoid target gene, is crucial for human skeletal muscle precursor cell survival. J Cell Sci. 2012; 125:6147-56.

8. Schönhofen P, de Medeiros LM, Chatain CP, et al. Cofilin/actin rod formation by dysregulation of cofilin-1 activity as a central initial step in neurodegeneration. Mini Rev Med Chem. 2014; 14:393-400.

9. Cambiazo V, González M, Isamit C, Maccioni RB. The beta-isoform of heat shock protein hsp-90 is structurally related with human microtubule-interacting protein Mip-90. FEBS Lett. 1999; 457:343-7.

10. Byrne JC, Downes MR, O'Donoghue N, et al. 2D-DIGE as a strategy to identify serum markers for the progression of prostate cancer. J Proteome Res. 2009; 8:942-57.
11. Katafigiotis I, Tyritzis SI, Stravodimos KG, et al. Zinc $\beta 2$-glycoprotein as a potential novel urine biomarker for the early diagnosis of prostate cancer. BJU Int. 2012; 110:E688-93.

12. Pin E, Fredolini C, Petricoin EF $3^{\text {rd }}$. The role of proteomics in prostate cancer research: biomarker discovery and validation. Clin Biochem. 2013; 46:524-38.

13. Dijkstra S, Mulders PF, Schalken JA. Clinical use of novel urine and blood based prostate cancer biomarkers: a review. Clin Biochem. 2014; 47:889-96.

14. Cary KC, Cooperberg MR. Biomarkers in prostate cancer surveillance and screening: past, present, and future. Ther Adv Urol. 2013; 5:318-29.

15. Eckersberger E, Finkelstein J, Sadri H, et al. Screening for prostate cancer: a review of the ERSPC and PLCO trials. Rev Urol. 2009; 11:127-33.

16. Andriole GL, Grubb RL 3 ${ }^{\text {rd }}$, Buys SS, et al. PLCO Project Team. Mortality results from a randomized prostate cancer screening trial. N Engl J Med. 2009; 360:1310-9.

17. Truong M, Yang B, Jarrard DF. Toward the detection of prostate cancer in urine: a critical analysis. J Urol. 2013; 189:422-9.

18. Beretov J, Wasinger VC, Schwartz P, et al. A standardized and reproducible urine preparation protocol for cancer biomarkers discovery. Biomark Cancer. 2014; 6:21-7

\author{
Correspondence \\ Amalia Katafigioti, MD \\ katafigiotis.giannis@gmail.com \\ Ioannis Katafigiotis, MD, MLS, PhD (Corresponding Author) \\ katafigiotis@yahoo.com \\ Christos Alamanis, MD \\ alamanis@otenet.gr \\ Konstantinos Stravodimos, MD \\ kgstravod@yahoo.com \\ Ioannis Anastasiou, MD \\ ekati2@otenet.gr \\ Eleni Roumelioti, MD \\ eleniroum81@gmail.com \\ Constantinos Constantinides, MD \\ ckonstan@med.uoa.gr \\ $2^{\text {st }}$ University Urology Clinic, Laiko Hospital \\ Agiou Thoma 17 Athens, Greece \\ Stavros Sfoungaristos, MD \\ sfoungaristosst@gmail.com \\ Mordechai Duvdevani, MD \\ moti_duv@yahoo.com \\ Hebrew Hadassah University Medical Center, Jerusalem, Israel
}

